\title{
Simultaneous bilateral hip replacement reveals superior outcome and fewer complications than two-stage procedures: a prospective study including 1819 patients and 5801 follow-ups from a total joint replacement registry
}

\author{
Emin Aghayev ${ }^{1 *}$, Andreas Beck², Lukas P Staub ${ }^{1}$, Daniel Dietrich ${ }^{3}$, Markus Melloh $^{4}$, Weniamin Orljanski ${ }^{5}$,
} Christoph Röder ${ }^{1,6}$

\begin{abstract}
Background: Total joint replacements represent a considerable part of day-to-day orthopaedic routine and a substantial proportion of patients undergoing unilateral total hip arthroplasty require a contralateral treatment after the first operation. This report compares complications and functional outcome of simultaneous versus early and delayed two-stage bilateral THA over a five-year follow-up period.

Methods: The study is a post hoc analysis of prospectively collected data in the framework of the European IDES hip registry. The database query resulted in 1819 patients with 5801 follow-ups treated with bilateral THA between 1965 and 2002. According to the timing of the two operations the sample was divided into three groups: I) 247 patients with simultaneous bilateral THA, II) 737 patients with two-stage bilateral THA within six months, III) 835 patients with two-stage bilateral THA between six months and five years.

Results: Whereas postoperative hip pain and flexion did not differ between the groups, the best walking capacity was observed in group I and the worst in group III. The rate of intraoperative complications in the first group was comparable to that of the second. The frequency of postoperative local and systemic complication in group I was the lowest of the three groups. The highest rate of complications was observed in group III.

Conclusions: From the point of view of possible intra- and postoperative complications, one-stage bilateral THA is equally safe or safer than two-stage interventions. Additionally, from an outcome perspective the one-stage procedure can be considered to be advantageous.
\end{abstract}

\section{Background}

Total joint replacements represent a large part of day-today orthopaedic routine. For the aging population, total hip arthroplasty (THA) has become a key treatment for re-establishing independence and quality of life. A substantial proportion of patients undergoing unilateral total hip arthroplasty require a contralateral treatment thereafter [1-3]. Since Ritter and Randolph (1976) performed

\footnotetext{
* Correspondence: emin.aghayev@memcenter.unibe.ch ${ }^{1}$ Institute for Evaluative Research in Orthopedic Surgery, University of Bern, Stauffacherstrasse 78, 3014 Bern, Switzerland

Full list of author information is available at the end of the article
}

the first detailed study of the functional outcome of simultaneous bilateral THA, there has been an ongoing discussion regarding benefits and disadvantages of onestage versus two-stage procedures [4]. A number of articles report advantages of simultaneous operations, or at least similar results of one-stage versus two-stage procedures [1,2,5-12]. The largest sample described consisted of 461 patients with a mean follow-up time of 3 years, although functional outcome was not assessed [10].

In 1965 M.E. Müller started a systematic collection of THA outcome data and developed a documentation system that culminated in IDES, the International 
Documentation and Evaluation System for total hip and knee arthroplasty. IDES and precursors have collected prospective information about 48,000 primary THA, 12,000 revision THA, and 77,000 follow-ups from 65 hospitals in Europe. The richness of information in the database makes possible comparison of different timings of bilateral THA.

In the current study we compared simultaneous bilateral THA (Group I) with early (within six months) (Group II) and delayed (within five years) two-stage bilateral THA (Group III) regarding complications and functional outcome over a five-year follow-up period. The two surgeries in the delayed two-stage group were separately analyzed. A large cohort of Charnley class A patients with unilateral THA were used as reference group for graphical comparisons.

\section{Methods}

Our study is based on the IDES (International Documentation and Evaluation System) hip registry of the Institute for Evaluative Research in Orthopaedic Surgery at the University of Bern. The history and administration of the registry have been previously described $[13,14]$. Table 1 shows the variables used for the analysis.

\section{Sample characteristics}

Institutional review board approval at our center was not required as it utilized existing anonymous observational data. The information was derived from 41 hospitals in 8 European countries (Switzerland, France, Germany, Italy, The Netherlands, Spain, Belgium, and Austria) where standardized datasets have been collected in a prospective, systematic and consecutive mode. All cases with bilateral THA operated between 1965 and 2002 and at least one follow-up per hip within the first five postoperative years were selected. If there were two or more follow-ups per year, the one closest to the middle of the year was selected. No case with revision was included. Patients with Charnley classes A (except for graphical comparisons) and $C$ were excluded since the first group has unilateral hip disease by definition and the latter group has comorbid conditions influencing the functional outcome [15]. Patients under 19 years of age were also excluded, but no other exclusions based upon the primary diagnosis were made. The database query resulted in 1819 patients with 5801 follow-ups (3.2 follow-ups per patient) within the first five postoperative years.

According to the timing of the two operations the patient sample was divided into three groups. The first group of 247 patients had undergone simultaneous bilateral THA. The second group of 737 patients had early two-stage bilateral THA, i.e. the second operation was
Table 1 International Documentation and Evaluation System variables used for the study

\begin{tabular}{|c|c|}
\hline Variable & Answer options \\
\hline \multicolumn{2}{|l|}{ Date of birth } \\
\hline \multicolumn{2}{|l|}{ Date of surgery } \\
\hline \multirow[t]{2}{*}{ Gender } & male \\
\hline & female \\
\hline \multirow[t]{2}{*}{ Operation side } & right \\
\hline & left \\
\hline \multirow[t]{5}{*}{ Diagnosis } & osteoarthritis \\
\hline & developmental displasia \\
\hline & inflammatory arthritis \\
\hline & fracture \\
\hline & miscellaneous \\
\hline \multirow[t]{5}{*}{ Pain } & none \\
\hline & mild \\
\hline & moderate \\
\hline & severe \\
\hline & intolerable \\
\hline \multirow[t]{5}{*}{ Walking capacity restriction } & $>60 \min$ \\
\hline & $31 \mathrm{~min}$ to $60 \mathrm{~min}$ \\
\hline & $10 \mathrm{~min}$ to $30 \mathrm{~min}$ \\
\hline & $<10 \min$ \\
\hline & impossible \\
\hline \multirow[t]{5}{*}{ Flexion } & $>90^{\circ}$ \\
\hline & $71^{\circ}$ to $90^{\circ}$ \\
\hline & $30^{\circ}$ to $70^{\circ}$ \\
\hline & $<30^{\circ}$ \\
\hline & stiff \\
\hline
\end{tabular}

\begin{tabular}{ll}
\hline Harris Hip Score & \\
\hline Intraoperative complications & none \\
& perforation \\
& proximal fracture \\
& distal fracture \\
& fracture of trochanter \\
& tendency to dislocate \\
& vascular \\
& pelvic perforation \\
& other \\
\hline Systemic postoperative complication & none \\
& deep thrombosis \\
& pulmonary embolism \\
& cardiovascular \\
& respiratory \\
& gastrointestinal \\
& urological \\
& CNS \\
& other \\
& none \\
Local postoperative complication & hematoma \\
& dislocation \\
& neuropraxia \\
&
\end{tabular}


Table 1 International Documentation and Evaluation System variables used for the study (Continued)

wound dehiscence

superficial

deep infection

sinus

other

Follow-up date

performed within six months after the first. The third group of 835 patients had delayed two-stage bilateral THA with an interval of six months to five years.

In addition to the 3 groups with bilateral hip disease, a $4^{\text {th }}$ reference group including patients with unilateral hip disease and no other comorbid condition affecting mobility and motion (Charnley class A) was created [15]. This reference group was comprised of 8402 patients and solely used for graphical comparisons. The graphical reference of this group wants to provide the reader with a visual comparison between the functional outcome of the three groups under study and the classical reference group of THA patients with an isolated and unilateral hip disease and no other condition affecting mobility and motion.

Outcome variables were pain, walking capacity, flexion, Harris Hip Score (HHS), a composite score summarizing items of pain, mobility, motion and some activities of daily living into a sum score from 0-100, [16] as well as intraoperative, systemic and local complications. Certain categories of pain and function from the IDES database were combined for our study. Pain was classified as none/mild, moderate, or severe/intolerable; walking capacity was classified as more than 60 minutes, 31-60 minutes, 10-30 minutes, or less than 10 minutes/not possible; the range of hip flexion was classified as $>90^{\circ}, 71^{\circ}-90^{\circ}, 30^{\circ}-70^{\circ}$, or $<30^{\circ} /$ stiff. We defined a desired outcome as no or mild hip pain, a walking capacity of longer than 60 minutes, and a range of hip flexion of $>90^{\circ}$. We hypothesized that the outcomes of the three groups with bilateral surgeries are affected by the timing of the second surgery in relation to the first one.

\section{Statistical analysis}

Chi-square test was used for comparing proportions between the study groups. All follow-up examinations were grouped on the basis of annual follow-up intervals. Multivariate modeling (generalized estimating equations method, GEE) was applied for globally assessing group differences with regard to outcome variables over time. Correction factors of gender, age, diagnosis, and baseline values were employed for the respective outcome variables. Additionally, for each outcome variable and each follow-up year the Cochran-Mantel-Haenszel test was used to compare the patient groups. Stratification factors were the same as for the multivariate model. Bonferroni-Holm adjustments for each outcome variable were set to account for multiple testing over the five follow-up years. The empirical proportions of desired outcomes and related $95 \%$ percent confidence intervals were plotted to graphically display the variability within the groups. The level of significance was set to 0.05 throughout the study. All statistical analyses were conducted using SAS 9.1 (SAS Institute Inc, Cary, NC).

\section{Literature review}

A systematic search of the literature was conducted to identify studies comparing simultaneous versus twostage bilateral THA. MEDLINE was searched with the following free text and MeSH search terms: hip arthroplasty, hip disease, bilateral THA, simultaneous OR one stage OR two stage THA. Additionally, the reference list of each eligible article was screened for other relevant publications (cross reference search) to identify additional studies. The articles were included if the aim of the study was to compare one versus two stage bilateral THA. There was no language, age or publication year restriction.

\section{Results}

The demographic characteristics of the study groups are shown in table 2.

\section{Comparison of groups - preoperative status}

Table 3 shows the distribution of diagnoses in the groups. Table 4 shows in bold the percentage of patients with severe or intolerable pain, walking capacity below 10 minutes, and hip flexion range below 30 degrees. The simultaneous group I had the lowest proportion of patients with severe/intolerable pain, and group II had the highest percentage of painful hips. The simultaneous group I had the least compromised preoperative ambulation; the second and third group were similar and considerably worse. Regarding range of motion the group III was the best and the worst was group II. Global inter-group differences were significant for hip pain, walking capacity and flexion ( $\mathrm{p}<0.001$ for all variables).

\section{Comparison of groups - outcome}

The excellent outcome regarding hip pain, walking endurance and flexion is shown in figures 1, 2 and 3 where the empirical frequencies (uncorrected for gender, age, diagnosis, and baseline values for respective outcome variables) are displayed. The reference group is displayed as dotted line (figures. 1, 2, 3). Whereas hip pain did not differ between the groups $(\mathrm{p}=0.1$, figure 1 ), the best walking capacity was observed in the simultaneous group I and the worst in group III after the first 
Table 2 Demographic characteristics of the studied groups

\begin{tabular}{lcccccc}
\hline & $\begin{array}{c}\text { Number of } \\
\text { patients }\end{array}$ & \multicolumn{2}{c}{ Age } & \multirow{2}{*}{$\begin{array}{c}\text { Proportion of } \\
\text { women }\end{array}$} & $\begin{array}{c}\text { Treated between } \\
\text { (ys) }\end{array}$ & $\begin{array}{c}\text { 80\% of treatments performed } \\
\text { between (ys) }\end{array}$ \\
\cline { 2 - 3 } & 247 & $22-85$ & 59 & $53 \%$ & $1978-2001$ & $1989-1999$ \\
\hline Group I & 737 & $20-88$ & 62 & $50 \%$ & $1968-2002$ & $1984-1999$ \\
\hline Group II & 835 & $22-87$ & 63 & $49 \%$ & $1980-1998$ & $1984-1994$ \\
\hline Group III & 8402 & $20-94$ & 65 & $51 \%$ & $1982-2000$ & $1985-1998$ \\
\hline $\begin{array}{l}\text { Reference group } \\
\text { (unilateral) }\end{array}$ & & & & & & \\
\hline
\end{tabular}

surgery ( $\mathrm{p}<0.001$, figure 3 ). Compared with the simultaneous group I, the odds for excellent walking capacities in group II were $0.49,0.25$ in group III after the first and 0.36 after the second surgery $(\mathrm{p}<0.001$ for all comparisons).

According to the GEE method there was a significant difference in range of postoperative hip flexion between at least two groups. The individual group comparisons did then show a significant difference between group III after the first surgery and group I ( $p<0.001$, figure 2 ). The odds for excellent flexion in group III after the first surgery were 0.63 compared with group I.

Similarly, group I had the best mean HHS (94.2, range 37-100), followed by group II (92.6, range 51-100) and group III after both surgeries (89.9, range 48-100). This difference in HHS was significant between groups I and III ( $\mathrm{p}<0.001)$, and II and III $(\mathrm{p}=0.040)$.

A separate intragroup comparison between the first and second surgery in group III showed significant difference regarding walking capacity $(\mathrm{p}<0.001)$ and hip flexion ( $p=0.009$ ). The odds for excellent walking capacity were 0.68 after the first surgery compared to the second one. For excellent flexion they were 0.77 after the first surgery.

\section{Comparison of groups - complications}

The simultaneous group I showed an intraoperative complication rate of $3.2 \%$ during the first operation and of $6.9 \%$ during the second one (table 5 ). Fracture of the trochanter was the most frequent complication during

Table 3 Distribution of diagnoses. Global inter-group difference was significant (chi-square test: $\mathbf{p}<\mathbf{0 . 0 0 1}$ )

\begin{tabular}{lccccccccc}
\hline & \multicolumn{2}{c}{$\begin{array}{c}\text { Group I: } \\
\mathbf{2 4 7}\end{array}$} & \multicolumn{2}{c}{$\begin{array}{c}\text { Group II: } \\
\mathbf{7 3 7}\end{array}$} & \multicolumn{2}{c}{$\begin{array}{c}\text { Group III: } \\
\mathbf{8 3 5}\end{array}$} & \multicolumn{2}{c}{$\begin{array}{c}\text { Group IV: } \\
\mathbf{8 4 0 2}\end{array}$} \\
\hline Diagnosis & $\mathbf{n}$ & $\mathbf{\%}$ & $\mathbf{n}$ & $\mathbf{\%}$ & $\mathbf{n}$ & $\mathbf{\%}$ & $\mathbf{n}$ & $\mathbf{\%}$ \\
\hline Osteoarthritis & 173 & $\mathbf{7 0 . 0}$ & 532 & $\mathbf{7 2 . 2}$ & 663 & $\mathbf{7 9 . 4}$ & 6391 & $\mathbf{7 6 . 1}$ \\
Dysplasy & 43 & $\mathbf{1 7 . 4}$ & 99 & $\mathbf{1 3 . 4}$ & 85 & $\mathbf{1 0 . 2}$ & 665 & $\mathbf{7 . 9}$ \\
Inflammation & 15 & $\mathbf{6 . 1}$ & 40 & $\mathbf{5 . 4}$ & 25 & $\mathbf{3 . 0}$ & 103 & $\mathbf{1 . 2}$ \\
Fracture & 1 & $\mathbf{0 . 4}$ & 9 & $\mathbf{1 . 2}$ & 6 & $\mathbf{0 . 7}$ & 689 & $\mathbf{8 . 2}$ \\
Miscellaneous & 15 & $\mathbf{6 . 1}$ & 57 & $\mathbf{7 . 7}$ & 56 & $\mathbf{6 . 7}$ & 554 & $\mathbf{6 . 6}$ \\
\hline
\end{tabular}

both the first (1.6\%) and the second operation (4.0\%). The trochanter fracture rate, an important complication for functional outcome, was the highest in group I $(5.7 \%$ in group I versus $3.5 \%$ in group II and $4.4 \%$ in group III after both operations) but not significantly different to the other groups neither in combined (OP1 + OP2) nor in separated comparisons.

With $10.5 \%$ the rate of postoperative systemic complications was the lowest of all groups (table 5). The most common complication was a urinary tract infection during hospital course (4.5\%).

Similarly, group I also had the lowest rate of postoperative local complications $(11.4 \%$ after both operations). A hematoma was the predominant local complication during both the first $(4.5 \%)$ and the second operation (4.9\%).

In group II the rate of intraoperative complications was higher than in group I during the first (5.4\%) but lower during the second (4.2\%) intervention (table 5 ). The most common complication also was a trochanter fracture $(1.8 \%$ for both the first and the second intervention).

Table 4 Preoperative pain, walking capacity and flexion

\begin{tabular}{lccc}
\hline & Group I: $\mathbf{2 4 7}$ & Group II: $\mathbf{7 3 7}$ & Group III: $\mathbf{8 3 5}$ \\
\hline Pain & & & \\
\hline none/mild & $6 \%$ & $4 \%$ & $2 \%$ \\
moderate & $34 \%$ & $26 \%$ & $31 \%$ \\
severe/intolerable & $\mathbf{6 0 \%}$ & $\mathbf{7 0 \%}$ & $\mathbf{6 7 \%}$ \\
\hline Walking capacity & & & \\
\hline$>60$ min & $11 \%$ & $6 \%$ & $5 \%$ \\
31 min to 60 min & $18 \%$ & $11 \%$ & $14 \%$ \\
10 min to 30 min & $26 \%$ & $18 \%$ & $17 \%$ \\
$<10$ min/impossible & $\mathbf{4 5 \%}$ & $\mathbf{6 5 \%}$ & $\mathbf{6 4 \%}$ \\
\hline Flexion & & & $14 \%$ \\
$>90^{\circ}$ & $19 \%$ & $9 \%$ & $48 \%$ \\
$71^{\circ}$ to $90^{\circ}$ & $39 \%$ & $42 \%$ & $31 \%$ \\
$30^{\circ}$ to $70^{\circ}$ & $31 \%$ & $36 \%$ & $\mathbf{7 \%}$ \\
$<30^{\circ} /$ stiff & $\mathbf{1 1 \%}$ & $\mathbf{1 3 \%}$ & \\
\hline
\end{tabular}

Global inter-group differences were significant for hip pain, walking capacity and flexion (chi-square test: $p<0.001$ for all three variables) 

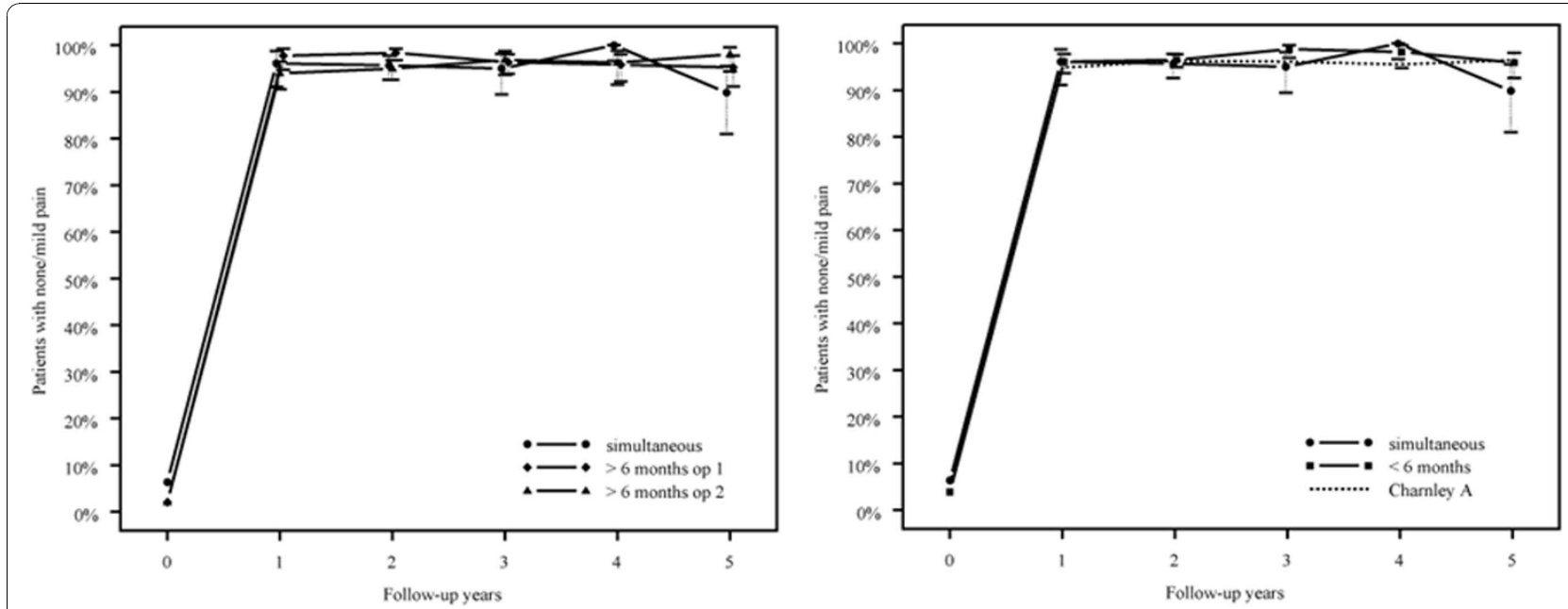

Figure 1 Proportion of patients with none/mild pain in the groups

The $13.9 \%$ of postoperative systemic complications were also higher than group I (table 5). The predominant complications were a urinary tract infection $(1.6 \%$ after the first and $1.9 \%$ after the second operation) and postoperative obstipation (1.8\% after the first and $1.1 \%$ after the second operation).

The sum of postoperative local complications after both operations was $12.4 \%$ (table 5 ). The predominant local complication was a hematoma during both the first $(5.2 \%)$ and the second operation (4.6\%).

Group III presented the highest total complication rates. There were $5.5 \%$ of intraoperative complications during the first and $5.6 \%$ during the second operation, while postoperative local complications were $6.7 \%$ after the first and $7.7 \%$ after the second intervention. Systemic complication rates were $10.8 \%$ after the first and $7.7 \%$ after the second operation (table 5). The most common intraoperative complication was fracture of the trochanter (1.9\% during the first and $2.5 \%$ during the second surgery). As in the other groups a hematoma was the most frequent postoperative local complication (5.3\% after the first and 5.9\% after the second surgery). The most common postoperative systemic complications were deep vein thrombosis, cardiovascular and urological complications summing up to $6.2 \%$ after the first and $4.6 \%$ after the second operation.

\section{Discussion}

We compared simultaneous bilateral THA with early and delayed two-stage bilateral THA regarding complications and functional outcome over a five-year followup period.

Lindberg and Sjöstrand (1972) estimated that approximately one-third of patients with primary osteoarthritis
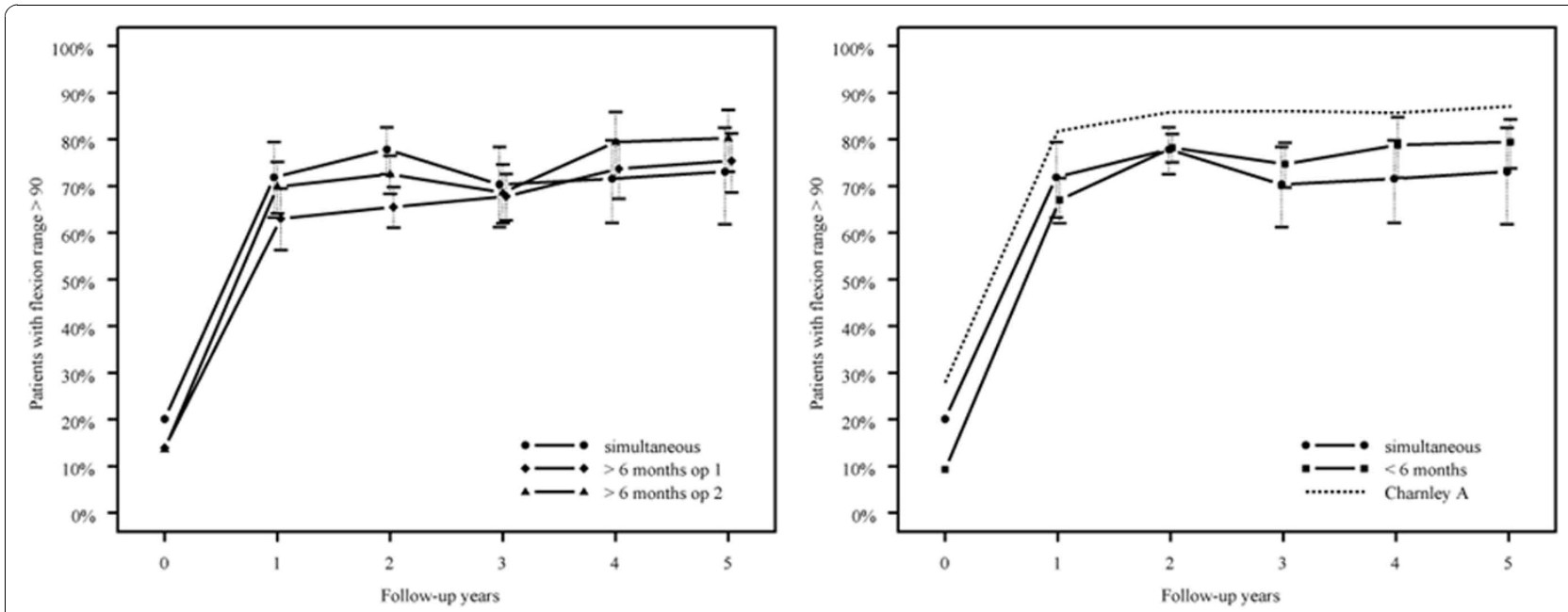

Figure 2 Proportion of patients with flexion range $>90^{\circ}$. 

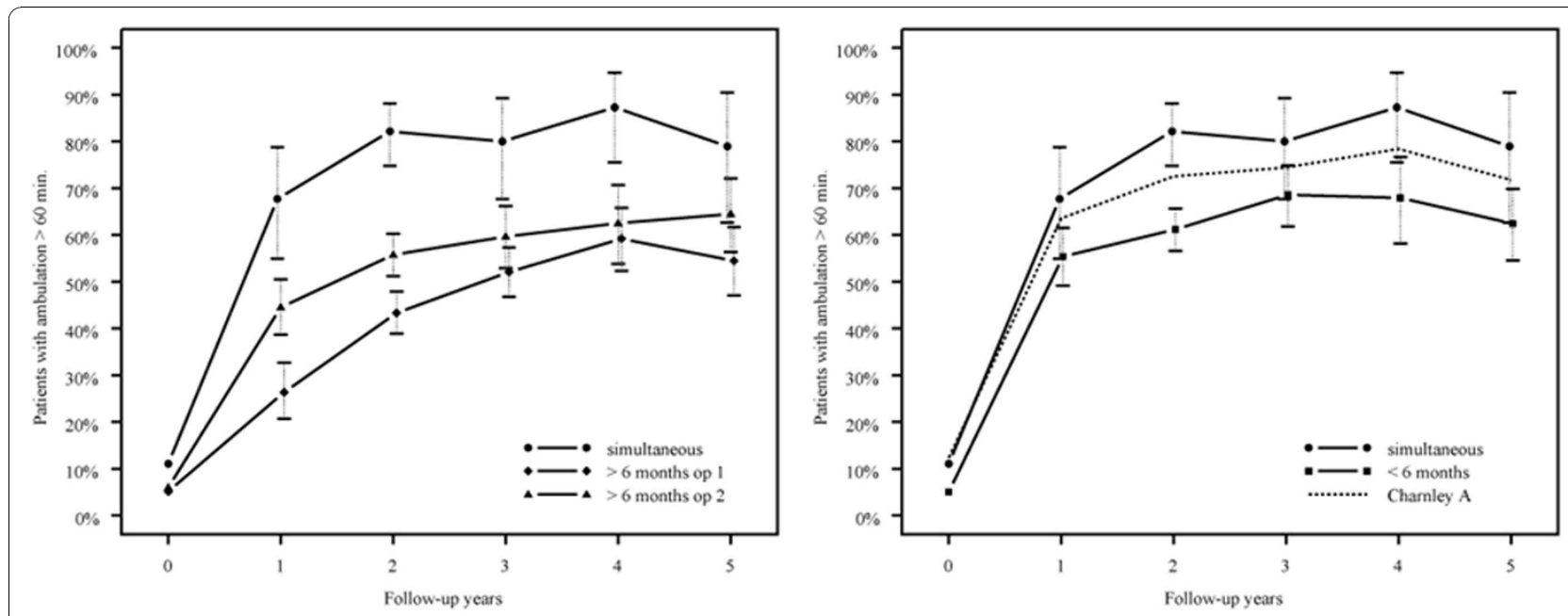

Figure 3 Proportion of patients with ambulation $>60 \mathrm{~min}$.

of the hips would need bilateral surgery [17]. This suggests the considerable importance of the comparison of one-stage versus two-stage bilateral THA.

In our study, a large number of European patients who had undergone bilateral total hip arthroplasty were analyzed in terms of three variables: walking endurance, hip pain and hip flexion range. Additionally, the rates of intraoperative and postoperative local and systemic complications and the Harris hip score were assessed.

Despite the differences regarding preoperative functional status, postoperative pain alleviation did not differ between the three groups during the first 5 follow-up

Table 5 Rate of complictions

\begin{tabular}{|c|c|c|c|c|c|c|c|c|c|}
\hline \multirow[b]{2}{*}{ IntaOP complications } & \multicolumn{3}{|c|}{ OP1 } & \multicolumn{3}{|c|}{ OP2 } & \multicolumn{3}{|c|}{$\mathrm{OP} 1+\mathrm{OP} 2$} \\
\hline & Group I & Group II & Group III & Group I & Group II & Group III & Group I & Group II & Group III \\
\hline shaft perforation & - & 1 & 2 & 1 & - & 2 & 1 & 1 & 4 \\
\hline proximal Fx & 2 & 4 & 9 & - & 2 & 9 & 2 & 6 & 18 \\
\hline Fx of trochanter & 4 & 13 & 16 & 10 & 13 & 21 & 14 & 26 & 37 \\
\hline tendency for luxation & - & 7 & 9 & 4 & 10 & 5 & 4 & 17 & 14 \\
\hline vascular injury & - & - & 2 & - & - & 1 & - & - & 3 \\
\hline pelvic perforation & - & 9 & 6 & 1 & 4 & 4 & 1 & 13 & 10 \\
\hline other & 2 & 6 & 3 & 1 & 2 & 6 & 3 & 8 & 9 \\
\hline total \% & 3.2 & 5.4 & 5.5 & 6.9 & 4.2 & 5.6 & 10.1 & 9.6 & 11.1 \\
\hline Systemic complications & Group I & Group II & Group III & Group I & Group II & Group III & Group I & Group II & Group III \\
\hline deep thrombosis & - & 6 & 16 & & 1 & 5 & - & 7 & 21 \\
\hline pulmonary emboly & 1 & 6 & 6 & & 4 & 3 & 1 & 10 & 9 \\
\hline cardiovascular & 3 & 5 & 14 & & 6 & 17 & 3 & 11 & 31 \\
\hline respiratory & - & 7 & 8 & & 1 & 3 & - & 8 & 11 \\
\hline gastrointestinal & 3 & 13 & 13 & & 8 & 9 & 3 & 21 & 22 \\
\hline urological & 11 & 12 & 25 & & 14 & 16 & 11 & 26 & 41 \\
\hline CNS & - & 3 & 5 & & 3 & 5 & - & 6 & 10 \\
\hline other & 8 & 6 & 5 & & 7 & 8 & 8 & 13 & 13 \\
\hline total \% & 10.5 & 7.9 & 10.8 & & 6.0 & 7.7 & 10.5 & 13.8 & 18.5 \\
\hline Local complications & Group I & Group II & Group III & Group I & Group II & Group III & Group I & Group II & Group III \\
\hline haematoma & 11 & 38 & 44 & 12 & 34 & 49 & 23 & 72 & 93 \\
\hline dislocation & 1 & 2 & 4 & 3 & 5 & 5 & 4 & 7 & 9 \\
\hline neuropraxia & - & 2 & 7 & 1 & 4 & 7 & 1 & 6 & 14 \\
\hline wound dehiscence & - & 5 & 2 & - & 1 & 5 & - & 6 & 7 \\
\hline total \% & 4.9 & 6.4 & 6.7 & 6.5 & 6.0 & 7.7 & 11.4 & 12.4 & 14.4 \\
\hline
\end{tabular}


years. Pain relief after THA is immediate, constant, and long-lasting, and it is independent of the preoperative pain level and demographic factors $[18,19]$.

In contrast, the proportion of patients walking longer than 60 minutes was $20 \%$ higher in the simultaneous group than in group II, and $28 \%$ higher than in group III at the 5 year follow-up. A possible explanation for this difference is the younger average age of group I which was 59 years, compared with 62 years in the second and with 63 years in the third groups. Moreover, unlike preoperative pain, preoperative walking capacity influences postoperative outcome and the preoperative walking capacity of group I was far better than that of the other groups [18]. Nevertheless, even after correction for preoperative condition and age in the statistical model the differences in walking capacity remained significant. In addition, the fact that patients with a simultaneous arthroplasty on both sides undergo only one rehabilitation and mobilization program seems advantageous. A single hospital stay is required for patients to learn to walk with altered proprioception, improved flexion range and pain alleviation. In contrast, bilateral hip disease with solely unilateral THA may also show clear improvement in postoperative walking endurancebut not the optimal one, since the contralateral untreated side remains painful and can limit overall function. Wykman and Olson stated that in bilateral hip disease, optimal function is not entirely regained until both hips have been replaced [20]. Optimal function can be achieved more quickly with a one-stage than the two-stage procedure [20]. Ritter et al. reported that in the contralateral osteoarthritic hip of a patient with one THA, the patient has a $78.5 \%$ chance of progression of his osteoarthritis and a $54 \%$ chance of requiring a second THA within 10 years [3]. Such a progression of contralateral osteoarthritis should be anticipated in patients with bilateral hip disease, which suggests treatment with simultaneous THA if the patient's overall health condition is permissive.

In group II, a second operation and yet another rehabilitation were undertaken after the first operation and the patient's habituation to the new prosthesis. In elderly people who make up a major part of the patients undergoing bilateral THA and who have a more limited habituation potential, a two-stage operation may result in suboptimal improvement of walking endurance. Weinstein et al. described one-stage bilateral THA as a safe and effective option even for patients over age 75 [21].

The comparison of the patients` status after the first and second operation in group III showed significantly different walking capacity and flexion in favor of the second intervention. Thus, in the time between the first and second operation, the patients with bilateral hip disease did not benefit from the full potential outcome of their therapy and though they were older after the second surgery their function improved beyond the status after the first THA. This is one of the main findings in favor of a consequent one-staged or early two-staged bilateral hip replacement intervention.

The possibly increased likelihood for intra- and postoperative local and systemic complications is the most frequently cited argument against simultaneous bilateral THA. In our study, however the analysis of complication rates showed an advantageous situation in group I with the simultaneously operated patients. The rate of intraoperative complications was comparable to that of group II; however, the frequency of postoperative local and systemic complications in group I was the lowest of all the three groups. The higher rate for trochanter fractures in group I during the second operation was not significantly different to that in the other groups. It did also not considerably influence the average postoperative pain, flexion and walking capacity after the simultaneous procedure. This may be explained by the fact that trochanteric fractures are mostly stable and do not require an additional treatment [22].

The worst group regarding complications was group III. The most prevalent complications were postoperative ones, including deep vein thrombosis and cardiovascular as well as urological events. These differences were observed despite the similar demographic characteristics of the groups. Parvizi also found that patients treated with two-stage bilateral THA arthroplasty had more complications, most commonly anemia and wound drainage [8].

In early publications comparing bilateral with unilateral THA, a higher incidence of pulmonary embolism and somewhat increased morbidity for bilateral THA was reported $[4,23,24]$. However, as concluded by Ritter and Stringer, the introduction of hypotensive anesthesia, improvement of operative environment, anticoagulation therapies, and early postoperative ambulation of patients have lead to a decrease in complication rates after bilateral THA [23]. In a detailed prospective study, Cammisa studied 35 adults with different preoperative status including myocardial infarction and pharmacologically controlled hypotension. The authors reported equal safety for both one-stage bilateral and unilateral THA without pulmonary emboli, myocardial infarctions, or other similar complications in the perioperative period [25]. Similarly, Salvati et al. found no differences in postoperative and long-term complications between one- and two-stage bilateral THA [10].

Literature concerning comparison of simultaneous and two-stage bilateral THA is summarized and compared in table 6. The 10 articles were published between 1978 and 2007 and they cover patients treated between 1970 and 2006. The studies included between 30 and 461 
Table 6 The found literature on comparison between one-stage and two-stage bilateral THA

\begin{tabular}{|c|c|c|c|c|c|c|c|c|c|c|}
\hline$N$ & Authors & Year & Period & Study & $\begin{array}{l}\text { Number } \\
\text { of pat. }\end{array}$ & $\begin{array}{l}\text { Inter- } \\
\text { operative } \\
\text { days }\end{array}$ & $\begin{array}{l}\text { FU } \\
\text { (months) }\end{array}$ & $\begin{array}{l}\text { Functional } \\
\text { outcome }\end{array}$ & Complications & Pro/contra \\
\hline 1 & $\begin{array}{l}\text { Alfaro- } \\
\text { Adriàn }\end{array}$ & 1999 & $\begin{array}{l}1989- \\
95\end{array}$ & $1 / 2$ stage & $\begin{array}{l}202(95 / \\
107)\end{array}$ & 0/60-730(300) & 0 & similar & >blood transfusions & $\begin{array}{l}\text { pro: <hospital stay, } \\
\text { costs }\end{array}$ \\
\hline 2 & $\begin{array}{l}\text { Berend } \\
\text { KR }\end{array}$ & 2007 & $\begin{array}{l}1997- \\
05\end{array}$ & $1 / 2$ stage & $\begin{array}{l}277(167 / \\
110)\end{array}$ & 0/14-730(240) & $30(6-108)$ & $\begin{array}{l}\text { early: } \\
<\text { function }\end{array}$ & $\begin{array}{l}\text { >blood transfusions } \\
\text { >revisions }\end{array}$ & $\begin{array}{l}\text { contra: } \\
\text { <reimbursement }\end{array}$ \\
\hline 3 & Bhan & 2006 & $\begin{array}{l}1996- \\
01\end{array}$ & 1/2 stage & $168(83 / 85)$ & $0 / 90-210$ & $60(48-96)$ & similar & $>$ blood transfusions & pro: $<$ hospital stay \\
\hline 4 & Eggli & 1996 & $\begin{array}{l}1982- \\
92\end{array}$ & $1 / 2$ stage & $\begin{array}{l}255(64 / 63 / \\
128)\end{array}$ & $0 />42 / 42-180$ & $>18$ & $\begin{array}{l}\text { similar; >stiff } \\
\text { hip }\end{array}$ & similar & $\begin{array}{l}\text { pro: <hospital stay, } \\
\text { costs }\end{array}$ \\
\hline 5 & McBryde & 2007 & $\begin{array}{l}1994- \\
06\end{array}$ & $1 / 2$ stage & $92(37 / 55)$ & $0 / 1-365$ & $\begin{array}{l}15(1-60) / 34 \\
(1-131)\end{array}$ & early better & $\begin{array}{l}\text { similar, >intubation } \\
\text { time }\end{array}$ & $\begin{array}{l}\text { pro: <hospital stay, } \\
\text { costs }\end{array}$ \\
\hline 6 & Parvizi & 2006 & $\begin{array}{l}1997- \\
04\end{array}$ & 1/2 stage & 196(98/98) & $0 / 25-303(138)$ & 0 & similar & $\begin{array}{l}<\text { blood transfusions } \\
<\text { complications }\end{array}$ & $\begin{array}{l}\text { pro: }<\text { costs, } \\
\text { >rehabilitation }\end{array}$ \\
\hline 7 & Reuben & 1998 & $\begin{array}{l}1991- \\
94\end{array}$ & $\begin{array}{l}1 / 2 \text { stage/ } \\
\text { unilat }\end{array}$ & $\begin{array}{l}\text { 154(7/8/ } \\
139)\end{array}$ & 0/7/unilat & 0 & - & - & pro: $<$ costs \\
\hline 8 & Salvati & 1978 & $\begin{array}{l}1970- \\
76\end{array}$ & $1 / 2$ stage & $\begin{array}{l}461(122 / \\
134 / 205)\end{array}$ & $\begin{array}{l}\text { 0/same hosp/ } \\
\text { 2nd hosp }\end{array}$ & $36(12-96)$ & similar & similar & $\begin{array}{l}\text { pro: <hospital stay, } \\
\text { costs, OP time }\end{array}$ \\
\hline 9 & Schiessel & 2005 & $\begin{array}{l}1996- \\
02\end{array}$ & $1 / 2$ stage & $30(15 / 15)$ & $0 / 120-665(485)$ & $66(S D$ 19.5) & $\begin{array}{l}\text { similar } \\
\text { (subjectively>) }\end{array}$ & similar & $\begin{array}{l}\text { pro: <hospital stay, } \\
\text { costs }\end{array}$ \\
\hline 10 & Shih & 1985 & $\begin{array}{l}1979- \\
82\end{array}$ & $1 / 2$ stage & $35(20 / 15)$ & 0/14-365 & $12 / 17.7$ & $\begin{array}{l}\text { similar but } \\
<\text { ROM }\end{array}$ & similar & $\begin{array}{l}\text { pro: <hospital stay, } \\
\text { OP time }\end{array}$ \\
\hline
\end{tabular}

The column "Study" shows the studied subgroups. The column "Number of patients" represents the total number of studied patients and number of subgroups in parentheses. The inter-operative interval for the subgroups is shown in the column "Inter-operative days" with mean values for the two-stage subgroup included in parentheses, if available. In the column "FU (month)" the mean follow-up time is given with the range of follow-up time or standard deviation (SD) in parentheses, if available. Note that " $>$ " and " $<$ " mean "more/better" respectively "less/worse" in the simultaneous subgroup.

patients and they show predominantly similar functional outcomes for simultaneous and two-stage procedures with a maximum average intraoperative interval of 1.82 years. Only Berend reporting on cementless bilateral THA documented a significantly increased need for postoperative inpatient rehabilitation services, as well as the fact that significantly fewer patients in the simultaneous group had met physical therapy goals before discharge to home [5]. In contrast, according to Schiessel patients prefer the simultaneous procedure because they undergo the process of operation, mobilization, and rehabilitation only once [11]. A better functional outcome after one-stage procedures is also reported for very stiff hips with a preoperative range of motion below $50^{\circ}$ [2].

The above mentioned articles report similar complication rates. However, Berend documented a significantly higher re-operation rate, more inpatient complications and adverse events in patients undergoing simultaneous bilateral THA in the lateral decubitus position although the author does not list them [5]. On the other hand, Parvizi reported fewer complications in the simultaneous group [8]. The remaining literature describes no significant differences in complication rates between simultaneous and two-stage bilateral THA.

Three out of 10 articles noticed a higher need for blood transfusion in the simultaneous group, whereas the article by Parvizi described a lower need $[1,5,6,8]$. McBryde noticed significantly longer anesthetic time in the simultaneous group than in two-stage procedure if compared to the time of each single operation. He accounted for this observation with the time needed to undrape, reposition the patient, redrape and prepare the patient again.

Out of 10 articles, 9 were in favor of simultaneous bilateral THA due to better cost efficiency, shorter hospital stay $(n=9)$ and shorter operation times $(n=2)$. Only Berend was against simultaneous bilateral THA [5]. His additional major argument was that of a lower potential reimbursement for hospital and surgeon [5].

Weinstein compared simultaneous bilateral THA in patients older and younger than 75 years [21]. Although, as expected, the older group owed more complications, the author documented excellent functional outcomes in both groups and concluded by favoring simultaneous bilateral THA, even for patients older than 75 years [21].

In the first group we had more patients with arthritis secondary to developmental dysplasia, which usually occurs earlier than primary coxarthritis, affecting mostly younger and more active individuals [11]. Nevertheless, the overall age distribution between the groups showed an average age difference of no more than three years. Concerning bilateral THA for dysplastic coxarthritis it is known that despite greater efforts in rehabilitation, 
patients prefer the simultaneous bilateral implantation since they need to undergo the process of operation, mobilization, and physiotherapy only once [11].

Our study has limitations that need to be considered when interpreting the results. We studied main outcome parameters such as walking endurance, pain, flexion, and complication rates. Obviously there are other outcome variables that depend on the timing of the two interventions. Further studies with the assessment of these variables are necessary for a more comprehensive comparison of the different possible operative intervals in bilateral THA. Furthermore, the study represents a retrospective analysis of prospectively, systematically and consecutively collected data. Despite this setup, the multitude of centers included and the large time frame carry with them the potential for selection bias in such a non-monitored data collection endeavor. If there is selection bias, however, it should rather be a nonsystematic one since none of the hospitals was aware of the goal of the current study and could have selectively included or excluded cases to their advantage. Therefore observed effects are rather diminished than amplified. Also, the simple fact of lack of detailed comorbidity reporting in the registry and hence impossibility to adjust for them in the statistical model may be responsible for higher prevalence for systemic complications in group III, since it could have been reasonable for patients under certain clinical conditions to undergo delayed two-stage procedures. We can therefore not clearly decide if comorbidity status or two the separate surgeries with anesthesia are responsible for this phenomenon.

It can be stereotypically concluded that a randomized controlled trial is the best option to study the effects of bilateral THA timing but given the restrictions of feasibility, cost, ethics, case numbers and follow-up time, a prospective cohort study, especially in the framework of a registry, may still be the best trade-off between invested efforts and resources and evidence level that the findings can generate.

\section{Conclusions}

Summarizing our results, from the point of view of possible intra- and postoperative complications, in patients with bilateral hip disease and adequate medical condition simultaneous bilateral total hip arthroplasty must be seen as equally safe or even safer than two-stage interventions. From an outcome perspective, the onestage procedures can be advantageous.

\section{List of abbreviations used}

THA: Total Hip Arthroplasty; IDES: International Documentation and Evaluation System; HSS: Harris Hip Score; GEE: generalized estimating equations method; OP: operation; UNILAT: unilateral; ROM: range of motion.

\section{Author details}

${ }^{1}$ Institute for Evaluative Research in Orthopedic Surgery, University of Bern, Stauffacherstrasse 78, 3014 Bern, Switzerland. '2Department of Orthopedic Surgery, Spital Langenthal, St. Urbanstrasse 67, 4901 Langenthal, Switzerland. ${ }^{3}$ Institute for Mathematical Statistics and Actuarial Science, University of Bern, Sidlerstrasse 5, 3012 Bern, Switzerland. ${ }^{4}$ Department of Orthopedic Surgery, University of Otago, Private Bag 1921, Dunedin, New Zealand. ${ }^{5}$ Department of Orthopedic Surgery, Vienna Private Clinic, Pelikangasse 15, 1090 Vienna, Austria. ${ }^{6}$ Department of Orthopedic Surgery, University of Bern, Freiburgstrasse 18, 3010 Bern, Switzerland.

\section{Authors' contributions}

EA is the principal investigator. He performed the study including statistical analysis and drafted the manuscript. $A B$ performed literature review and helped in drafting manuscript. LS and DD participated in the statistical analysis. MM and WO supervised the study and drafting the manuscript. CR conceived the study and participated in coordination and supervision of the study. All authors participated in the study design as well as read and approved the final manuscript.

Competing interests

The authors declare that they have no competing interests.

Received: 6 March 2010 Accepted: 25 October 2010

Published: 25 October 2010

\section{References}

1. Alfaro-Adrian J, Bayona F, Rech JA, Murray DW: One- or two-stage bilateral total hip replacement. J Arthroplasty 1999, 14(4):439-445.

2. Eggli S, Huckell CB, Ganz R: Bilateral total hip arthroplasty: one stage versus two stage procedure. Clin Orthop Relat Res 1996, 328:108-118.

3. Ritter MA, Carr K, Herbst SA, Eizember LE, Keating EM, Faris PM, Meding JB: Outcome of the contralateral hip following total hip arthroplasty for osteoarthritis. J Arthroplasty 1996, 11(3):242-246.

4. Ritter MA, Randolph JC: Bilateral total hip arthroplasty: a simultaneous procedure. Acta Orthop Scand 1976, 47(2):203-208

5. Berend KR, Lombardi AV Jr, Adams JB: Simultaneous vs staged cementless bilateral total hip arthroplasty: perioperative risk comparison. $J$ Arthroplasty 2007, 22(6 Suppl 2):111-115.

6. Bhan S, Pankaj A, Malhotra R: One- or two-stage bilateral total hip arthroplasty: a prospective, randomised, controlled study in an Asian population. J Bone Joint Surg Br 2006, 88(3):298-303.

7. McBryde CW, Dehne K, Pearson AM, Treacy RB, Pynsent PB: One- or twostage bilateral metal-on-metal hip resurfacing arthroplasty. J Bone Joint Surg Br 2007, 89(9):1144-1148.

8. Parvizi J, Tarity TD, Sheikh E, Sharkey PF, Hozack WJ, Rothman RH: Bilateral total hip arthroplasty: one-stage versus two-stage procedures. Clin Orthop Relat Res 2006, 453:137-141.

9. Reuben JD, Meyers SJ, Cox DD, Elliott M, Watson M, Shim SD: Cost comparison between bilateral simultaneous, staged, and unilateral total joint arthroplasty. J Arthroplasty 1998, 13(2):172-179.

10. Salvati EA, Hughes P, Lachiewicz P: Bilateral total hip-replacement arthroplasty in one stage. J Bone Joint Surg Am 1978, 60(5):640-644.

11. Schiessel A, Brenner M, Zweymuller K: [Bilateral hip joint replacement as a one-stage or two-stage procedure for dysplastic coxarthritis: a comparative analysis of 30 patients]. Z Orthop Ihre Grenzgeb 2005, 143(6):616-621.

12. Shih $\mathrm{CH}, \mathrm{Ho}$ WB: One-stage versus two-stage bilateral autophor ceramic total hip arthroplasty. Clin Orthop Relat Res 1985, 193:141-145.

13. Roder C, Eggli S, A EL-K, Muller U, Ambrose T, Roosli E, Busato A, Aebi M: The International Documentation and Evaluation System (IDES)-10-years experience. Int Orthop 2003, 27(5):259-261.

14. Paterson D: The International Documentation and Evaluation System (IDES). Orthopedics 1993, 16(1):11-14.

15. Charnley J: The long-term results of low-friction arthroplasty of the hip performed as a primary intervention. J Bone Joint Surg Br 1972, 54(1):61-76.

16. Harris WH: Traumatic arthritis of the hip after dislocation and acetabular fractures: treatment by mold arthroplasty. An end-result study using a new method of result evaluation. J Bone Joint Surg Am 1969, 51(4):737-755. 
17. Lindberg L, Sjostrand LO: [The future needs of hip surgery. Prognosis for Lund 1972-1980]. Lakartidningen 1972, 69(37):4109-4112.

18. Roder C, Staub LP, Eggli S, Dietrich D, Busato A, Muller U: Influence of preoperative functional status on outcome after total hip arthroplasty. $J$ Bone Joint Surg Am 2007, 89(1):11-17.

19. Roder C, Parvizi J, Eggli S, Berry DJ, Muller ME, Busato A: Demographic factors affecting long-term outcome of total hip arthroplasty. Clin Orthop Relat Res 2003, 417:62-73

20. Wykman A, Olsson E: Walking ability after total hip replacement. A comparison of gait analysis in unilateral and bilateral cases. J Bone Joint Surg Br 1992, 74(1):53-56.

21. Weinstein MA, Keggi JM, Zatorski LE, Keggi KJ: One-stage bilateral total hip arthroplasty in patients $>$ or $=75$ years. Orthopedics 2002, 25(2):153-156

22. Pritchett JW: Fracture of the greater trochanter after hip replacement. Clin Orthop Relat Res 2001, 390:221-226.

23. Ritter MA, Stringer EA: Bilateral total hip arthroplasty: a single procedure. Clin Orthop Relat Res 1980, 149:185-190.

24. Bracy D, Wroblewski BM: Bilateral Charnley arthroplasty as a single procedure. A report on 400 patients. J Bone Joint Surg Br 1981, 63$B(3): 354-356$.

25. Cammisa FPOBS Jr, Salvati EA, Sculco TP, Wilson PD Jr, Ranawat CS, Pellicci PM, Inglis AE: One-stage bilateral total hip arthroplasty. A prospective study of perioperative morbidity. Orthop Clin North Am 1988, 19(3):657-668

\section{Pre-publication history}

The pre-publication history for this paper can be accessed here: http://www.biomedcentral.com/1471-2474/11/245/prepub

doi:10.1186/1471-2474-11-245

Cite this article as: Aghayev et al: Simultaneous bilateral hip replacement reveals superior outcome and fewer complications than two-stage procedures: a prospective study including 1819 patients and 5801 follow-ups from a total joint replacement registry. BMC

Musculoskeletal Disorders 2010 11:245.

\section{Submit your next manuscript to BioMed Central} and take full advantage of:

- Convenient online submission

- Thorough peer review

- No space constraints or color figure charges

- Immediate publication on acceptance

- Inclusion in PubMed, CAS, Scopus and Google Scholar

- Research which is freely available for redistribution 